\title{
Transfer and distribution of amoxicillin in the rat gastric mucosa and gastric juice and the effects of rabeprazole
}

\author{
Hai-lun ZHENG, Yong-mei HU, Jun-jun BAO, Jian-ming XU* \\ Department of Gastroenterology, the First Affiliated Hospital of Anhui Medical University; the Key Laboratory of Gastroenterology of \\ Anhui Province, Hefei 230032, China
}

\begin{abstract}
Aim: To investigate the distribution of amoxicillin in the gastric juice and gastric mucosa of rats and to investigate the effects of proton pump inhibitor rabeprazole on amoxicillin concentrations in various compartments.

Methods: One hundred and sixty anesthetized rats were divided into five groups, and given intravenously different doses of amoxicillin or amoxicillin and rabeprazole. The $\mathrm{pH}$ value and volume of gastric juice was aspirated were measured and separated gastric mucosa was homogenized. The concentrations of amoxicillin in the plasma, gastric juice and gastric mucosa were measured by high performance liquid chromatography (HPLC).

Results: The maximum concentrations of amoxicillin in gastric juice and gastric mucosa were significantly lower than those in plasma $(P<0.001)$. Concentrations in the glandular stomach mucosa were higher than those in the forestomach mucosa. Rabeprazole did not significantly change the pharmacokinetic parameters of amoxicillin in the plasma and did not alter gastric antibiotic clearance or the gastric transfer fraction of amoxicillin in gastric juice. However, rabeprazole did increase the amoxicillin concentration and $\mathrm{pH}$ value in gastric juice and reduced the volume of the gastric juice.

Conclusion: Amoxicillin could penetrate the gastric mucosa and achieve therapeutic concentrations at the target site after transfer from the blood to the stomach. Rabeprazole increased the amoxicillin concentration in gastric juice by decreasing the gastric juice volume but did not affect its concentration in blood or gastric mucosa.
\end{abstract}

Keywords: amoxicillin; rabeprazole; Helicobacter pylori; gastric mucosa

Acta Pharmacologica Sinica (2010) 31: 501-508; doi: 10.1038/aps.2009.191; published online 22 Mar 2010

\section{Introduction}

The key role of Helicobacter pylori (H pylori) in the pathogenesis of chronic gastritis, peptic ulcers, gastric cancer and mucosaassociated lymphoid tissue lymphoma is well recognized ${ }^{[1,2]}$. The treatment guidelines recommended for $H$ pylori are a standard triple therapy consisting of clarithromycin and amoxicillin or metronidazole in combination with a proton pump inhibitor $(\mathrm{PPI})^{[3]}$. In the stomach, $H$ pylori lives in the mucus layer and also adheres to gastric epithelial cells ${ }^{[4,5]}$. Therefore, the antibiotics used to eliminate $H$ pylori must achieve inhibitory or bactericidal concentrations at the site of infection. The antibiotics are usually taken orally, and thus the thickness of the mucus layer, the shape and motility of the stomach, and the acidic environment may all contribute to inadequate distribution and concentration of the drugs at the

\footnotetext{
* To whom correspondence should be addressed.

E-mail xjm1017@hotmail.com

Received 2009-08-06 Accepted 2009-12-07
}

surface of the gastric mucosa ${ }^{[6]}$. When treating $H$ pylori infections by oral administration, some areas of the stomach, such as the crypts and folds of the gastric body or the transitional zones between the different gastric zones, are not sufficiently exposed to locally acting drugs ${ }^{[7]}$. H pylori in these areas may escape the effects of antibiotics. Access to these areas requires drug penetration via the bloodstream into the stomach. The lifespan of the local distribution of antibiotics in eradication regimens is short, and in addition to local delivery, the antibiotics are absorbed from the small intestine and are rapidly redistributed by the bloodstream to the gastric mucosa and gastric juice $^{[7]}$. Hence it is very important that antibiotics are transported from the bloodstream into the gastric mucosa and juice.

However, the transfer mechanisms of antibiotics from the bloodstream to the stomach, the antibiotic concentration in the gastric mucosa and juice, and the possible interaction between antibiotics and PPIs have not been carefully explored, and the pharmacokinetics is also poorly understood ${ }^{[7,8]}$. Investigating 
the transport of antibiotics to the stomach is important for the design of novel therapies and to understand the possible interaction between antibiotics and PPIs in various antimicrobial combinations used in clinical practice.

$H$ pylori is becoming increasingly resistant to antibiotics ${ }^{[9,10]}$, but the prevalence of resistance to amoxicillin is rare, occurring between 0 and $1 \%$, and has not increased over time. Thus, this antibiotic is an essential eradication regimen in clinical practice $^{[9,11]}$. Rabeprazole, a proton pump inhibitor, has been used for the treatment of $H$ pylori due to its many advantages, including the fact that its pharmacokinetics and pharmacodynamics are not influenced by CYP2C19 genetic polymorphisms ${ }^{[12]}$. Moreover, its onset of action is faster than other PPIs ${ }^{[13]}$. Nevertheless, the effects of rabeprazole on the transfer and distribution of amoxicillin in the gastric mucosa and gastric juice are not clear. The purpose of the present study was to determine the distribution and transport of amoxicillin in rat stomach and the effects of rabeprazole on the pharmacokinetics of amoxicillin.

\section{Materials and methods}

\section{Animals and groups}

Specific pathogen-free (SPF)-grade male Wistar rats, weighing $220 \pm 20 \mathrm{~g}$, were obtained from the Beijing Vital River Laboratory Animal Technology Co Ltd (Beijing, China; Certificate No SCXK 2007-0001). The rats were treated in accordance with the Guide for the Care and Use of Laboratory Animals published by the US National Institutes of Health in 1996. The rats were fasted for $24 \mathrm{~h}$ with free access to water prior to experimentation. The rats were distributed randomly into five groups (32 rats per group) and treated as follows: (i) control group (Control): 0.9\% physiological saline bolus; (ii) amoxicillin (Sigma Co, USA) 50 mg/kg bolus (Am 50); (iii) amoxicillin $100 \mathrm{mg} / \mathrm{kg}$ bolus (Am 100); (iv) amoxicillin $200 \mathrm{mg} / \mathrm{kg}$ bolus (Am 200); and (v) amoxicillin $200 \mathrm{mg} / \mathrm{kg}$ and rabeprazole (Aosaikang medicinal group, China. Batch No 080606) 4 $\mathrm{mg} / \mathrm{kg}$ bolus (Am 200+Ra). There were 8 sampling points in each group as follows: $0.25,0.5,0.75,1.0,1.25,1.5,1.75$, and $2 \mathrm{~h}$. Thirty-two rats from each group were randomly divided into eight subgroups (four rats per subgroup), and there were four rats (one subgroup) for each sampling point.

\section{Preparation of model}

The stomach and duodenum of the rats were exposed under anesthesia at laparotomy. Anesthesia was induced with a 2.7-mL/ kg intraperitoneal dose of a 1:1:2 (v:v:v) mixture of Hypnorm (fentanyl/fluanisone), midazolam, and physiological saline. Vital signs were monitored using an intracarotid blood pressure transducer and a multi-channel physiological recorder connected to a computer recording system. The duodenum was incised by an electrosurgical unit to avoid bleeding, and a soft rubber cannula was inserted through the duodenal incision into the gastric antrum via pylorus. The stomach was gently lavaged about five to eight times with this cannula with $1.0-\mathrm{mL}$ aliquots of $0.9 \%$ saline until the aspirate was free of debris, and then $1.0 \mathrm{~mL}$ of saline was instilled. The abdominal operative incision was covered with moistened tissue and clean carbasus. The body temperature was maintained at $37^{\circ} \mathrm{C}$ by a heating pad. After a 30-min equilibration period to allow gastric blood flow to stabilize, the saline in the stomach was aspirated, the cannula was pulled out, and the pyloric portion of stomach was gently taken out and occluded with a ligature, avoiding ligation of blood vessels. Drugs were given as intravenous boluses via the tail vein. At each sampling point after administration, a blood sample was drawn from the abdominal aorta. The rats were sacrificed by neck dislocation, the stomach was excised by the electrosurgical unit, and gastric juice was collected $2 \mathrm{~h}$ after the drugs were administrated. The volume of gastric juice was measured and recorded, and its $\mathrm{pH}$ value was determined by a $\mathrm{pH}$ meter and recorded.

\section{The study of antibiotic transport}

The stomach was opened along the lesser curvature and rinsed with $0.9 \%$ physiological saline. The gastric mucosa was separated from the submucosal layer by blistering with an injector. The tip of a $27 \mathrm{G}$ needle was inserted just below the submucosal layer, and physiological saline was injected between the layers under a light microscope. The process was repeated as many times as necessary to blister the entire area. Fine scissors were then used to cut the gastric mucosa along the boundary of the forestomach and the glandular stomach. The mucosa from different regions was weighed using an electronic analytical balance, and the net weight was recorded. The mucosa was homogenized, and the mucosa homogenate was diluted 10 -fold with $0.9 \%$ physiological saline ${ }^{[14,15]}$. All samples were separated immediately by centrifugation at $1600 \times g$ at $4{ }^{\circ} \mathrm{C}$ for $10 \mathrm{~min}$ after removal. The supernatant of the gastric juice, gastric mucosa and plasma were removed and stored immediately in a $-80{ }^{\circ} \mathrm{C}$ freezer until analysis. Rats were excluded from analysis in the event of a positive reaction to the occult blood test for the gastric juice or bleeding from the site of the duodenal incision or pylorus ligation.

\section{Antibiotic analysis}

Concentrations of amoxicillin in plasma, gastric juice and gastric mucosa samples were determined by modified high performance liquid chromatography (HPLC) according to previous publications ${ }^{[16,17]}$. The HPLC system consisted of a Waters 2695 Binary Pump solvent delivery system and a 2489 UV/Visible Detector (Waters, Massachusetts, USA). A Phenomenex Luna C18 column ( $4.6 \mathrm{~mm} \times 250 \mathrm{~mm}, 5 \mu \mathrm{m}$ particle size) was used as the analysis column with a guard column SecurityGuard C18 (4 mm×3 mm, $5 \mu \mathrm{m}$ particle size) (Phenomenex, California, USA). The column temperature was $30{ }^{\circ} \mathrm{C}$. The detection wavelength was $230 \mathrm{~nm}$ with 0.01 AUFS for the plasma samples and 0.001 AUFS for the gastric juice and gastric mucosa samples. The mobile phase consisted of phosphate buffer ( $\mathrm{pH} 3.40,0.02 \mathrm{~mol} / \mathrm{L})$ and methanol (95:5, $v / v$ ) in the current study instead of acetonitrile as in previous $\operatorname{methods}^{[16,17]}$. The flow rate was $1 \mathrm{~mL} / \mathrm{min}$. Aliquots of $10-\mu \mathrm{L}$ samples were used for analysis. Control samples were pre- 
pared by spiking plasma and $0.9 \%$ physiological saline with stock amoxicillin solutions. The limit of quantitation was 0.10 $\mathrm{mg} / \mathrm{L}$ in plasma and $0.01 \mathrm{mg} / \mathrm{L}$ in gastric juice and gastric mucosa. The correlation coefficients (r) for calibration curves were equal to or better than 0.9989. Quality control (QC) samples of fixed concentrations of amoxicillin were prepared to determine the intra- and inter-day precision and accuracy of the assay. The precision of the method was determined as the intra- and inter-day variability of low, medium and high concentration QC samples. The accuracy was evaluated by the relative bias of the calculated concentrations of the QC samples compared with their theoretical values. Intra-day data were collected from an analysis of three batches of QC samples on the same day, and inter-day data were collected from the analysis of the QC samples on six separate days. The inter- and intra-day relative standard deviations (RSDs) were less than $3.1 \%$. The relative biases of the calculated concentrations of the QC samples compared with their theoretical values were less than $2.6 \%$. The stability of amoxicillin in the samples was examined by comparing the determined concentration at different times for up to four weeks at $-80^{\circ} \mathrm{C}$ and following three thaw-freeze cycles. Amoxicillin was stable in the matrices for up to four weeks at $-80^{\circ} \mathrm{C}$ without significant degradation (RSDs $<3.8 \%$ ), and after three thaw-freeze cycles the RSDs were less than $4.1 \%$. The absolute recovery was calculated by comparing the peak area obtained from prepared sample extracts with those found by direct injection of drug solution made in $0.9 \%$ physiological saline at the same concentration. The mean absolute recovery of amoxicillin in plasma was $98.3 \%$, and it was higher than $99.1 \%$ in gastric juice and gastric mucosa.

\section{Calculations and statistics}

Sample statistics were calculated using SPSS 11.5 software (SPSS Inc, USA). Pharmacokinetic parameters were analyzed using the drug and statistics software 2.0 (DAS) and the statistical moment method. The significance of differences was evaluated by ANOVA and Mann-Whitney tests. A $P$-value less than 0.05 was regarded as significant for all statistical tests performed.

Gastric antibiotic clearance (in $\mathrm{mL} / \mathrm{min}$ ) for the 120-min experiments was calculated as follows:

Gastric clearance $=\sum$ (Gastric juice volume per $\min \times$ antibiotic concentration $)_{0-2 \mathrm{~h}} /$ Plasma $\mathrm{AUC}_{0-2 \mathrm{~h}}{ }^{[18]}$.

The gastric transfer fraction was calculated by dividing the gastric clearance by the plasma clearance. Gastric Transfer Fraction $(\%)=$ Gastric Clearance $/$ Plasma Clearance

Both parameters enable a description of the relative transfer of antibiotics across the gastric mucosa under different experimental conditions by correcting for intersubject variation in plasma antibiotic concentrations ${ }^{[19]}$.

\section{Results}

Amoxicillin pharmacokinetic parameters and the effect of rabeprazole

The vital signs of the rats were stable during the experiment.
The pharmacokinetic parameters for amoxicillin in plasma were similar in the single treatment group with an amoxicillin dose of $200 \mathrm{mg} / \mathrm{kg}$ and in the combination treatment group with an amoxicillin dose of $200 \mathrm{mg} / \mathrm{kg}$ and rabeprazole $4 \mathrm{mg} / \mathrm{kg}$, as assessed by $\mathrm{AUC}_{0-2} \mathrm{~h}, \mathrm{AUC}_{0-\infty}, C_{\max }$ and $T_{1 / 2}$ (Table 1).

Table 1. Effects of rabeprazole on amoxicillin pharmacokinetic parameters in rat plasma following a single $200 \mathrm{mg} / \mathrm{kg}$ intravenous bolus of amoxicillin with or without rabeprazole. $\mathrm{AUC}_{0-2 \mathrm{~h}}$ and $\mathrm{AUC}_{0-\infty}$ : area under the time-concentration curves from 0 to $2 \mathrm{~h}$ for amoxicillin and extrapolated to infinite, respectively. $T_{1 / 2}$ : half-life. $C_{\max }$ : maximum plasma concentration. Am 200: amoxicillin 200 mg/kg group. Am 200+Ra: amoxicillin 200 $\mathrm{mg} / \mathrm{kg}+$ rabeprazole $4 \mathrm{mg} / \mathrm{kg}$ group. $n=32$. Mean \pm SD.

\begin{tabular}{|c|c|c|}
\hline \multirow[t]{2}{*}{ Variables } & \multicolumn{2}{|c|}{ Group } \\
\hline & Am 200 & Am 200+Ra \\
\hline$A \cup C_{0-2 h}\left(m g \cdot L^{-1} \cdot h^{-1}\right)$ & $719.85 \pm 46.23$ & $\begin{array}{l}723.79 \pm 78.56 \\
(P=0.8076 \text { vs Am } 200 \text { group })\end{array}$ \\
\hline$A U C_{0-\infty}\left(m g \cdot L^{-1} \cdot h^{-1}\right)$ & $1125.46 \pm 60.32$ & $\begin{array}{l}1119.07 \pm 18.90 \\
(P=0.5674 \text { vs Am } 200 \text { group })\end{array}$ \\
\hline$T_{1 / 2}(\mathrm{~h})$ & $1.42 \pm 0.06$ & $\begin{aligned} & 1.35 \pm 0.05 \\
(P= & 0.1246 \text { vs Am } 200 \text { group })\end{aligned}$ \\
\hline$C_{\max }(\mathrm{mg} / \mathrm{L})$ & $496.38 \pm 54.62$ & $\begin{array}{c}517.33 \pm 31.35 \\
(P=0.1499 \text { vs Am } 200 \text { group })\end{array}$ \\
\hline
\end{tabular}

\section{Effect of amoxicillin and rabeprazole on the gastric juice $\mathrm{pH}$ value}

The analysis of the gastric juice $\mathrm{pH}$ data $2 \mathrm{~h}$ post-administration indicated that the mean $\mathrm{pH}$ value observed when the groups received only amoxicillin was not significantly different from the mean $\mathrm{pH}$ observed in the control group (2.46 \pm 0.49$)$. This was also the case for gastric juice $\mathrm{pH}$ values among the three different amoxicillin dosage groups, and their mean values were $2.44 \pm 0.60$ in the Am 50 group, $2.41 \pm 0.78$ in the Am 100 group, and $2.59 \pm 0.68$ in the Am 200 group (Figure $1)$. In the amoxicillin combined with rabeprazole group, the mean $\mathrm{pH}$ value $(5.82 \pm 1.10)$ was significantly higher than the

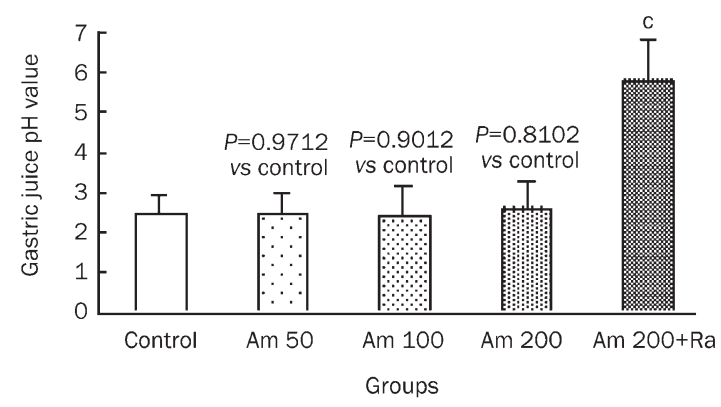

Figure 1. Effects of amoxicillin and rabeprazole on gastric juice $\mathrm{pH}$ value. Control: control group; Am 50: amoxicillin 50 mg/kg bolus group; Am 100: amoxicillin 100 mg/kg bolus group; Am 200: amoxicillin 200 mg/kg bolus group; Am 200+Ra: amoxicillin $200 \mathrm{mg} / \mathrm{kg}+$ rabeprazole $4 \mathrm{mg} / \mathrm{kg}$ bolus group. $n=32$. Mean \pm SD. ${ }^{c} P<0.01$ vs others groups. 
control group and in the groups treated with only amoxicillin $(P<0.05$, Figure 1$)$.

\section{Effect of amoxicillin and rabeprazole on gastric juice volume} In the control group, the gastric juice volume was $1.937 \pm 0.087$ $\mathrm{mL}$. The three amoxicillin-only treated groups did not differ significantly from the control group for gastric juice volume (Figure 2). The gastric juice volume in the Am 200+Ra group $(1.224 \pm 0.128 \mathrm{~mL})$ was significantly reduced compared to the control group and the amoxicillin-treated groups (Figure 2).

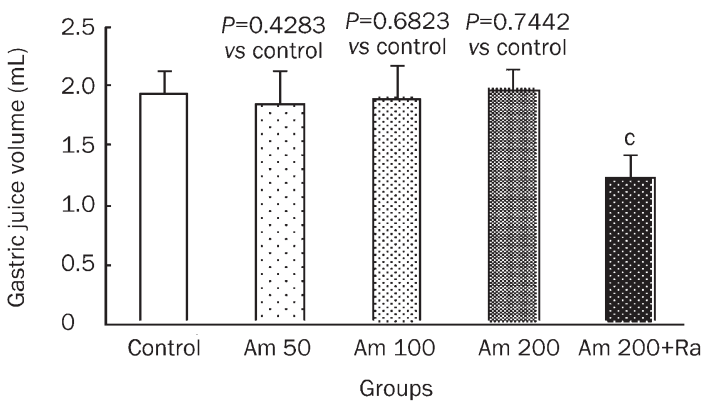

Figure 2. Effects of amoxicillin and rabeprazole on gastric juice volume. Control: control group; Am 50: amoxicillin 50 mg/kg bolus group; Am 100: amoxicillin 100 mg/kg bolus group; Am 200: amoxicillin 200 mg/kg bolus group; Am 200+Ra: amoxicillin $200 \mathrm{mg} / \mathrm{kg}+$ rabeprazole $4 \mathrm{mg} / \mathrm{kg}$ bolus group. $n=32$. Mean \pm SD. ${ }^{c} P<0.01$ vs others groups.

\section{Amoxicillin concentration in gastric juice and the effect of rabeprazole}

In the three different amoxicillin dosage regimens, the maximum concentration of amoxicillin in gastric juice was significantly lower than that in plasma $(P<0.001$; Table 2$)$. The amoxicillin concentration in gastric juice increased as the amoxicillin dosage increased (Figure 3). Rabeprazole significantly raised the amoxicillin concentration in the gastric juice of the Am $200+$ Ra group compared with the group treated with the same dose of amoxicillin (Figure 3). However, rabeprazole did not

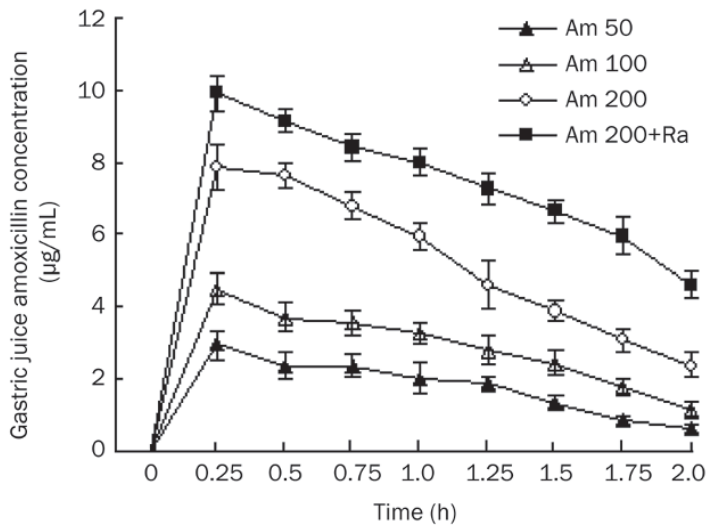

Figure 3. Gastric juice amoxicillin concentration and the effects of rabeprazole on them. Am 50: amoxicillin $50 \mathrm{mg} / \mathrm{kg}$ group. Am 100: amoxicillin 100 mg/kg group. Am 200: amoxicillin 200 mg/kg group. Am 200+Ra: amoxicillin 200 mg/kg+rabeprazole 4 mg/kg group. $n=32$. Mean \pm SD. Amoxicillin concentration in gastric juice increased with amoxicillin dosage stepping up at the same sampling point $(P<0.01)$. Gastric juice amoxicillin concentration in Am 200 group was higher than that in Am 200+Ra group at the same sampling point $(P<0.01)$.

remarkably change the gastric clearance or the gastric transfer fraction of amoxicillin (Table 2).

\section{Amoxicillin concentration in gastric mucosa and the effect of rabeprazole}

The amoxicillin concentration in the gastric mucosa was significantly lower than that in the plasma $(P<0.001)$. The concentration of amoxicillin in the glandular stomach mucosa was higher than that in the forestomach mucosa at the same sampling point for every group treated with only amoxicillin. The amoxicillin concentration increased according to an increase in dosage (Figure 4). The amoxicillin concentration in the forestomach mucosa and in the glandular stomach mucosa increased with an increase in amoxicillin dosage (Figure 5). Rabeprazole did not significantly change the concentration of amoxicillin in the gastric mucosa (Figure 5).

Table 2. Gastric amoxicillin transfer and the effects of rabeprazole on amoxicillin transfer. Am 50: amoxicillin $50 \mathrm{mg} / \mathrm{kg}$ group. Am 100: amoxicillin 100 mg/kg group. Am 200: amoxicillin 200 mg/kg group. Am 200+Ra: amoxicillin 200 mg/kg+rabeprazole 4 mg/kg group. $n=32 . \quad$ Mean $\pm S D$.

\begin{tabular}{|c|c|c|c|c|}
\hline Group & Am 50 & Am 100 & Am 200 & Am 200+Ra \\
\hline Gastric juice $C_{\max }(\mathrm{mg} / \mathrm{L})$ & $2.95 \pm 0.38$ & $\begin{array}{c}4.49 \pm 0.41 \\
(P<0.01 \text { vs Am } 50 \text { group })\end{array}$ & $\begin{array}{l}7.85 \pm 0.65 \\
(P<0.01 \text { vs Am } 100 \text { and } \\
\text { Am } 50 \text { group })\end{array}$ & $\begin{array}{c}9.91 \pm 0.52 \\
(P<0.01 \text { vs Am } 200 \text { group })\end{array}$ \\
\hline Gastric clearance $(\mu \mathrm{L} / \min )$ & $286.01 \pm 6.43$ & $\begin{array}{l}306.57 \pm 17.79 \\
(P<0.01 \text { vs Am } 50 \text { group })\end{array}$ & $\begin{array}{l}208.38 \pm 11.99 \\
(P<0.01 \text { vs Am } 100 \text { and } \\
\text { Am } 50 \text { group })\end{array}$ & $\begin{array}{l}215.64 \pm 13.20 \\
(P=0.2688 \text { vs Am } 200 \text { group })\end{array}$ \\
\hline Gastric transfer fraction (\%) & $2.05 \pm 0.50$ & $\begin{array}{c}1.29 \pm 0.71 \\
(P<0.01 \text { vs Am } 50 \text { group })\end{array}$ & $\begin{array}{l}1.89 \pm 0.22 \\
(P<0.01 \text { vs Am } 100 \text { group; } \\
P=0.4213 \text { vs Am } 50 \text { group })\end{array}$ & $\begin{array}{c}1.73 \pm 0.44 \\
(P=0.3576 \text { vs Am } 200 \text { group })\end{array}$ \\
\hline
\end{tabular}



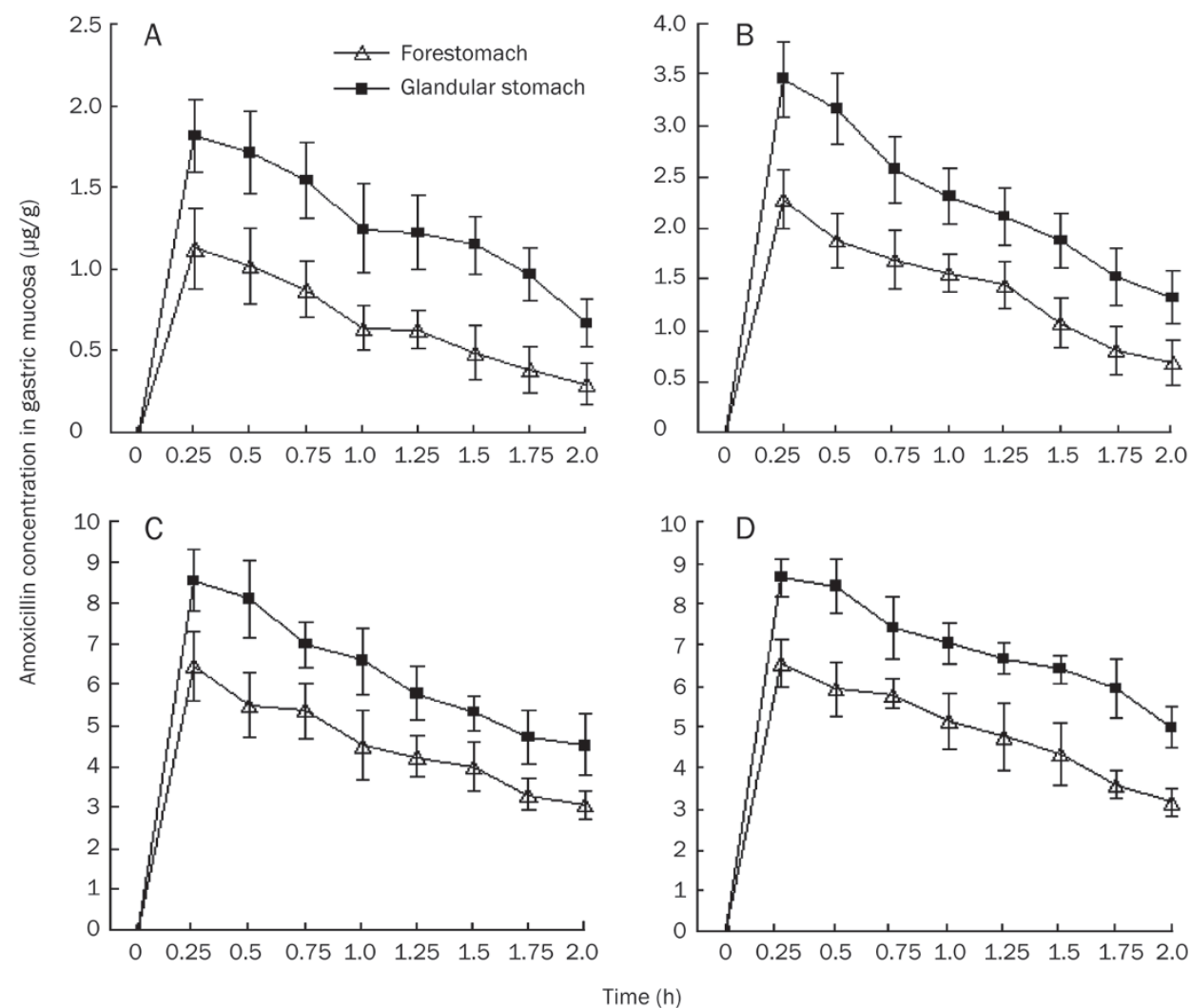

Figure 4. Concentration of different dosage amoxicillin in forestomach mucosa and in the glandular stomach mucosa and the effect of rabeprazole on them. (A) Amoxicillin $50 \mathrm{mg} / \mathrm{kg}$ group. (B) Amoxicillin $100 \mathrm{mg} / \mathrm{kg}$ group. (C) Amoxicillin $200 \mathrm{mg} / \mathrm{kg}$ group. (D) Amoxicillin $200 \mathrm{mg} / \mathrm{kg}+\mathrm{rabeprazole} 4$ $\mathrm{mg} / \mathrm{kg}$ group. $n=32$. Mean \pm SD. Amoxicillin concentration in the glandular stomach mucosa was higher than that in the forestomach mucosa at the same sampling point in every groups $(P<0.01)$.
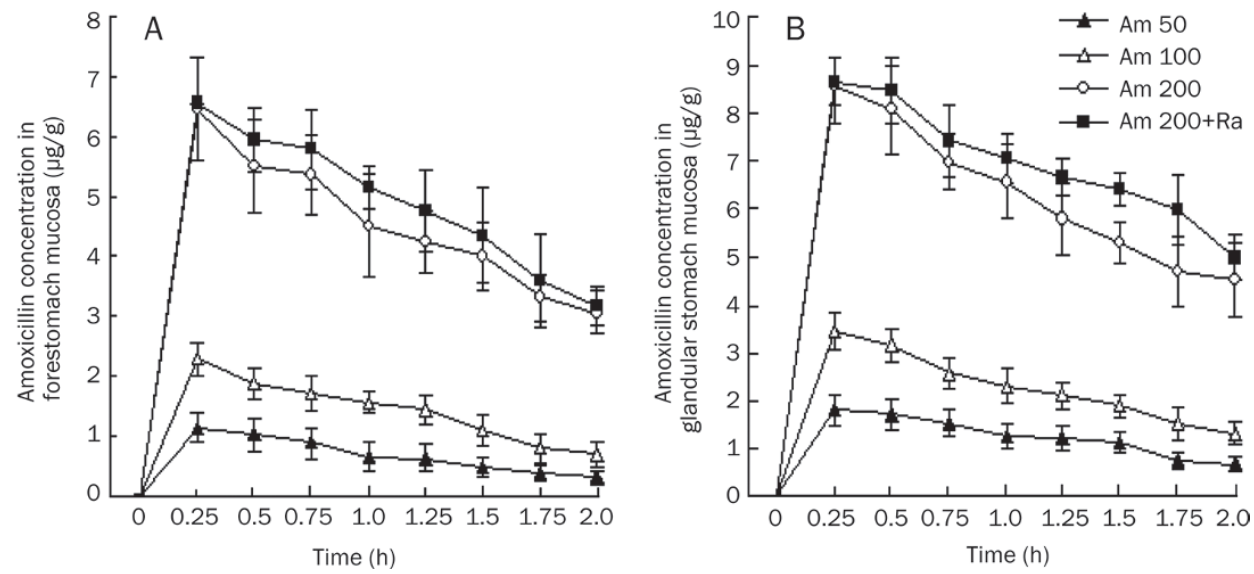

Figure 5. Amoxicillin concentration in the forestomach mucosa and the glandular stomach mucosa and the effect of rabeprazole on them. (A) Forestomach mucosa. (B) Glandular stomach mucosa. Am 50: amoxicillin 50 mg/kg group. Am 100: amoxicillin 100 mg/kg group. Am 200: amoxicillin $200 \mathrm{mg} / \mathrm{kg}$ group. Am 200+Ra: amoxicillin $200 \mathrm{mg} / \mathrm{kg}+$ rabeprazole $4 \mathrm{mg} / \mathrm{kg}$ group. $n=32$. Mean \pm SD. Amoxicillin concentration in the forestomach mucosa $(A)$ and in the glandular stomach mucosa $(B)$ increased with amoxicillin dosage stepping up at the same sampling point $(P<0.01)$. Amoxicillin concentration in the forestomach mucosa or in the glandular stomach mucosa in Am 200 group was not significantly differently than that in Am $200+\mathrm{Ra}$ group at the same sampling point $(P>0.05)$.

\section{Discussion}

The eradication of $H$ pylori in vivo is difficult because $H$ pylori attaches to the gastric epithelial surface, and antibiotics do not always achieve bactericidal concentrations within and 
beneath the gastric mucus ${ }^{[20]}$. Amoxicillin has always been the antibiotic of choice in standard triple therapy and in sequential treatment for eradicating $H$ pylori due to its low resistance rates and effectiveness ${ }^{[21]}$. The lifespan of the local distribution of amoxicillin in the stomach is very short after oral administration, and because $H$ pylori can evade amoxicillin treatment ${ }^{[22]}$, it is very important to study the systemic distribution of amoxicillin and the effect of PPIs after absorption from the small intestine. A model consisting of intravenous administration provides an opportunity for the exploration of the effects of systemic amoxicillin distribution on its gastric transfer and distribution from the bloodstream to the stomach. It is not clear whether amoxicillin is transferred from the blood to the stomach irrespective of $H$ pylori status or acid blockade by omeprazole ${ }^{[23-25]}$. This controversy may be related to a low dosage of amoxicillin, the small number of subjects included in most studies, or the analytical methods used. An in vitro result reported that amoxicillin can be transported from the epithelial basal layer to the apical layer via paracellular transport or transcellular transport ${ }^{[26]}$. Several other data also indicate that amoxicillin is transported to the gastric mucosa or gastric juice $^{[14,19,25,27,28]}$. In contrast, another report demonstrated that no amoxicillin was detected in gastric juice or gastric mucosa after intravenous administration ${ }^{[23,29]}$.

In the present experiments, three different doses, high (200 mg/kg), middle (100 mg/kg) and low (50 mg/kg), were adopted to avoid the possibility of insufficient dosage, and an animal model was modified according to reported methods $^{[11,18,30]}$. The anaesthetized rat model provides an opportunity to investigate the mechanisms of gastric antibiotic transfer. In contrast to human studies, no pyloric loss or bile contamination of gastric juice and mucosa occurs, and the gastric transport of novel compounds can be readily evaluated ${ }^{[18]}$. The blistering method of dissecting the gastric mucosa ensures that the mucosa sample is not contaminated by blood in the micrangium below the gastric mucosa. An occult blood test for the gastric juice was used to preclude blood contamination.

The present experimental results indicated that amoxicillin can be transported from the blood to the rat stomach, although the gastric transfer fraction is very low. The systemic transport of amoxicillin to the gastric lumen from the blood is restricted with an antibiotic $C_{\max }$ concentration gradient for amoxicillin from the blood to gastric juice of about 100:1 for rats treated with amoxicillin or amoxicillin and rabeprazole. This may partly explain the contradictions among previous reports, and our study suggests that amoxicillin can not be detected if the dosage is too low. Indeed, only very small amounts of amoxicillin were transferred from the blood to the stomach following intravenous administration, especially with lower amoxicillin doses. The amoxicillin concentration in the stomach increased when the dosage was increased, and this suggests that high doses of the drug should be used in eradication therapy of pylori $^{[3]}$.

The minimal inhibitory concentrations of amoxicillin for 90\% (MIC90, $\mu \mathrm{g} / \mathrm{mL}$ ) of known H pylori strains are lower than $0.03 \mu \mathrm{g} / \mathrm{mL}^{[31,32]}$, and we found that amoxicillin concentrations in gastric juice and gastric mucosa are far higher than 0.03 $\mu \mathrm{g} / \mathrm{mL}$. The amoxicillin dosage used in rats for the study was derived from dosage requirements in humans. As such, this suggests that the systemic effects of amoxicillin can induce the eradication of $H$ pylori in humans. Earlier reports showed that amoxicillin can induce the eradication of $H$ pylori after intravenous administration ${ }^{[33,34]}$, suggesting that eradication of the bacteria may be achieved by a systemic effect of amoxicillin. However, the mechanism of transport is not fully understood. Amoxicillin does not accumulate in cells and crosses the epithelium either via the paracellular pathway or via the transcellular pathway. Moreover, as a low molecular weight zwitterion (molecular weight $365 \mathrm{~g} / \mathrm{mol}$ ), amoxicillin may cross negatively charged tight junctions and favor paracellular diffusion across the epithelium ${ }^{[26]}$. Amoxicillin can be secreted into gastric mucosa or into gastric juice by gastric parietal cells in the isthmus after intravenous administration, although the secreted amount is very small. Therefore, compared with penetration, the secretion of amoxicillin may contribute little to the eradication of $H$ pylori ${ }^{[25]}$.

Amoxicillin is an amphoteric drug, containing both a basic $\left(-\mathrm{NH}_{2}\right)$ and an acidic (-COOH) group (pKa 2.4 and 7.2). A greater proportion of the molecule is in the un-ionized form at alkaline $\mathrm{pH}$ and at very acidic $\mathrm{pH}$, and this may enhance the lipid solubility of amoxicillin. A therapy regimen based on rabeprazole and amoxicillin has long been used to eradicate $H$ pylori infection ${ }^{[35-37]}$. However, the effects of rabeprazole on the concentration of amoxicillin in gastric juice and gastric tissue have not been previously reported. In the current study, we found that although the co-administration of amoxicillin with rabeprazole does not change the pharmacokinetic parameters for amoxicillin in the blood, it results in higher amoxicillin concentrations in the gastric juice. When rabeprazole is administered concurrently with amoxicillin, the stomach $\mathrm{pH}$ is elevated due to the inhibition of rabeprazole in gastric parietal cell $\mathrm{H}^{+} / \mathrm{K}^{+}$adenosine triphosphatase (ATPase). Higher gastric $\mathrm{pH}$ may reduce chemical degradation and increase the stability of amoxicillin, resulting in the potentiation of antimicrobial activity of this antibiotic against $H$ pylori ${ }^{[38]}$. The increase in gastric $\mathrm{pH}$ may also increase the proportion of amoxicillin in the un-ionized form, leading to enhanced lipid solubility, which allows amoxicillin to more easily penetrate the gastric epithelium from the blood to the stomach ${ }^{[38]}$.

The reduction of gastric juice volume in the group coadministered rabeprazole and amoxicillin compared with the group treated only with amoxicillin resulted in an increased amoxicillin concentration in the gastric juice. This is further supported by the finding that rabeprazole does not significantly change the gastric clearance and gastric transfer fraction of amoxicillin in the gastric juice. These results are similar to those found with another proton pump inhibitor, omeprazole, which potentiates amoxicillin monotherapy efficacy against $H$ pylori by reducing the volume of gastric secretion and hence effectively increasing the drug concentration in the gastric juice $^{[19]}$. The results in the present study indicate that small amounts of amoxicillin were transferred from the blood to the 
gastric juice following intravenous administration. Rabeprazole did not significantly change the pharmacokinetic parameters of amoxicillin in the blood. Nevertheless, rabeprazole increased the amoxicillin concentrations in gastric juice. This suggests that the increase in amoxicillin concentrations in the gastric juice is predominantly caused by reduced gastric juice volume, which occurs during treatment with rabeprazole.

Our results indicate that amoxicillin can penetrate the gastric epithelium, and the antibiotic can achieve therapeutic concentrations at the target site after being transferred from the blood. Moreover, an increased amoxicillin dosage can increase drug concentrations in the gastric juice and the gastric mucosa. Rabeprazole increases the amoxicillin concentration in the gastric juice but does not alter its concentration in the blood or gastric mucosa, which indicates that the increase is mediated primarily by decreasing the volume of the gastric juice. These results also provide support for the high dosage of amoxicillin that is used to eradicate H pylori.

\section{Acknowledgements}

This work was supported by the Natural Sciences Research Foundation from the Department of Education of Anhui Province, China (№ KJ 2008B064).

\section{Author contribution}

Hai-lun ZHENG designed and carried out the research. Jianming XU and Yong-mei HU designed the research; Hai-lun ZHENG, Yong-mei HU, and Jun-jun BAO performed the research; Hai-lun ZHENG and Yong-mei HU analyzed the data. Hai-lun ZHENG wrote the paper.

\section{References}

1 Konturek JW. Discovery by Jaworski of Helicobacter pylori and its pathogenetic role in peptic ulcer, gastritis and gastric cancer. J Physiol Pharmacol 2003; 54: 23-41.

2 Megraud F, Lehours P. Helicobacter pylori detection and antimicrobial susceptibility testing. Clin Microbiol Rev 2007; 20: 280-322.

3 Malfertheiner P, Mégraud F, O'Morain C, Bazzoli F, El-Omar E, Graham D, et al. Current concepts in the management of Helicobacter pylori infection: the Maastricht III Consensus Report. Gut 2007; 56: 77281.

4 Yoshiyama H, Nakazawa T. Unique mechanism of Helicobacter pylori for colonizing the gastric mucus. Microbes Infect 2000; 2: 55-60.

5 Henriksnäs J, Phillipson M, Storm M, Engstrand L, Soleimani M, Holm L. Impaired mucus-bicarbonate barrier in Helicobacter pylori-infected mice. Am J Physiol Gastrointest Liver Physiol 2006; 291: 396-403.

6 Van Zanten SJ, Kolesnikow T, Leung V, O'Rourke JL, Lee A. Gastric transitional zones, areas where Helicobacter treatment fails: results of a treatment trial using the Sydney strain mouse model. Antimicrob Agents Chemother 2003; 7: 2249-55.

7 Nakamura M, Spiller RC, Barrett DA, Wibawa JI, Kumagai N, Tsuchimoto K, et al. Gastric juice, gastric tissue and blood antibiotic concentrations following omeprazole, amoxicillin and clarithromycin triple therapy. Helicobacter 2003; 8: 294-9.

8 Pedrazzoli J Jr, Calafatti SA, Ortiz RA, Dias FE, Deguer M, Mendes $\mathrm{FD}$, et al. Transfer of clarithromycin to gastric juice is enhanced by omeprazole in Helicobacter pylori-infected individuals. Scand J Gastroenterol 2001; 36: 1248-53.
9 Mégraud F. H pylori antibiotic resistance: prevalence, importance, and advances in testing. Gut 2004; 53: 1374-84.

10 Pajares García JM, Pajares-Villarroya R, Gisbert JP. Helicobacter pylori infection: antibiotic resistance. Rev Esp Enferm Dig 2007; 99: 63-70.

11 Gerrits MM, van Vliet AH, Kuipers EJ, Kusters JG. Helicobacter pylori and antimicrobial resistance: molecular mechanisms and clinical implications. Lancet Infect Dis 2006; 6: 699-709.

12 Sakai T, Aoyama N, Kita T, Sakaeda T, Nishiguchi K, Nishitora Y, et al. CYP2C19 genotype and pharmacokinetics of three proton pump inhibitors in healthy subjects. Pharm Res 2001; 18: 721-7.

13 Besancon M, Simon A, Sachs G, Shin JM. Sites of reaction of the gastric $\mathrm{H}$, K-ATPase with extracytoplasmic thiol reagents. J Biol Chem 1997; 272: 22438-46.

14 Goddard AF, Erah PO, Barrett DA, Shaw PN, Spiller RC. The effect of protein binding and lipophilicity of penicillins on their in-vitro flux across gastric mucosa. J Antimicrob Chemother 1998; 41: 231-6.

15 Hammer TA, Sandvik AK, Waldum HL. Potentiating hypergastrinemic effect by the peroxisome proliferator ciprofibrate and omeprazole in the rat. Scand J Gastroenterol 1998; 33: 595-9.

16 Du X, Li C, Sun HK, Nightingale CH, Nicolau DP. A sensitive assay of amoxicillin in mouse plasma and broncho-alveolar lavage fluid by liquid-liquid extraction and reversed-phase HPLC. J Pharm Biomed Anal 2005; 39: 648-52.

17 Pires de Abreu LR, Ortiz RM, de Castro SC, Pedrazzoli J Jr. HPLC determination of amoxicillin comparative bioavailability in healthy volunteers after a single dose administration. J Pharm Pharm Sci 2003; 6: 223-30.

18 Sherwood PV, Wibawa JI, Atherton JC, Jordan N, Jenkins D, Barrett $\mathrm{DA}$, et al. Impact of acid secretion, gastritis, and mucus thickness on gastric transfer of antibiotics in rats. Gut 2002; 51: 490-5.

19 Goddard AF, Jessa MJ, Barrett DA, Shaw PN, Idström JP, Cederberg $\mathrm{C}$, et al. Effect of omeprazole on the distribution of metronidazole, amoxicillin, and clarithromycin in human gastric juice. Gastroenterology 1996; 111: 358-67.

20 Graham DY. Therapy of Helicobacter pylori: current status and issues. Gastroenterology 2000; 118: S2-8.

21 Rokkas T, Sechopoulos P, Robotis I, Margantinis G, Pistiolas D. Cumulative $H$ pylori eradication rates in clinical practice by adopting first and second-line regimens proposed by the Maastricht III consensus and a third-line empirical regimen. Am J Gastroenterol 2009; 104: 21-5.

22 Atherton JC, Cockayne A, Balsitis M, Kirk GE, Hawkey CJ, Spiller RC. Detection of the intragastric sites at which Helicobacter pylori evades treatment with amoxycillin and cimetidine. Gut 1995; 36: 670-4.

23 Ortiz RA, Calafatti SA, Corazzi A, Souza JM, Deguer M, De Souza $\mathrm{CA}$, et al. Amoxicillin and ampicillin are not transferred to gastric juice irrespective of Helicobacter pylori status or acid blockade by omeprazole. Aliment Pharmacol Ther 2002; 16: 1163-70.

24 Endo H, Yoshida H, Kohno Y, Suga T. Effects of clarithromycin and amoxicillin on gastric emptying in rats. Antimicrob Agents Chemother 2002; 46: 3331-3.

25 Endo $\mathrm{H}$, Yoshida $\mathrm{H}$, Ohmi $\mathrm{N}$, Ohta $\mathrm{K}$, Higuchi S. Localization of $\left[{ }^{14} \mathrm{C}\right]$ amoxicillin in rat gastric tissue when administered with lansoprazole and clarithromycin. J Antimicrob Chemother. 2001; 48: 923-6.

26 Matysiak-Budnik T, Heyman M, Candalh C, Lethuaire D, Mégraud F. In vitro transfer of clarithromycin and amoxicillin across the epithelial barrier: effect of Helicobacter pylori. J Antimicrob Chemother 2002; 50: 865-72.

27 Lozniewski A, de Korwin JD, Muhale F, Jehl F. Gastric diffusion of antibiotics used against $H$ pylori. Int J Antimicrob Agents 1997; 9: 181-93. 
28 Lozniewski A, Duprez A, Renault C, Muhale F, Conroy MC, Weber M, et al. Gastric penetration of amoxicillin in a human Helicobacter pyloriinfected xenograft model. Antimicrob Agents Chemother 1999; 43: 1909-13.

29 Van Zanten SJ, Goldie J, Hollingsworth J, Silletti C, Richardson H, Hunt $\mathrm{RH}$. Secretion of intravenously administered antibiotics in gastric juice: implications for management of Helicobacter pylori. J Clin Pathol 1992; 45: 225-7.

30 Kurasawa T, Chikaraishi Y, Naito A, Toyoda Y, Notsu Y. Effect of humulus lupulus on gastric secretion in a rat pylorus-ligated model. Biol Pharm Bull 2005; 28: 353-7.

31 Lang L, García F. Comparison of E-test and disk diffusion assay to evaluate resistance of Helicobacter pylori isolates to amoxicillin, clarithromycin, metronidazole and tetracycline in Costa Rica. Int J Antimicrob Agents 2004; 24: 572-7.

32 Wolle K, Leodolter A, Malfertheiner P, König W. Antibiotic susceptibility of Helicobacter pylori in Germany: stable primary resistance from 1995 to 2000. J Med Microbiol 2002; 51: 705-9.

33 Adamek RJ, Wegener M, Opferkuch W, Rühl GH. Successful Helicobacter pylori eradication: a systemic effect of antibiotics. Am J
Gastroenterol 1993; 88: 792-3.

34 Adamek RJ, Wegener M, Labenz J, Freitag M, Opferkuch W, Rühl GH. Medium-term results of oral and intravenous omeprazole/amoxicillin Helicobacter pylori eradication therapy. Am J Gastroenterol 1994; 89: 39-42.

35 Murakami K, Okimoto T, Kodama M, Sato R, Watanabe K, Fujioka T. Evaluation of three different proton pump inhibitors with amoxicillin and metronidazole in retreatment for Helicobacter pylori infection. J Clin Gastroenterol 2008; 42: 139-42.

36 Kuwayama H, Asaka M, Sugiyama T, Fukuda Y, Aoyama N, Hirai Y, et al. Rabeprazole-based eradication therapy for Helicobacter pylori: a large-scale study in Japan. Aliment Pharmacol Ther 2007; 25: 1105-13.

37 Sharara Al, Chaar HF, Aoun E, Abdul-Baki H, Araj GF, Kanj SS. Efficacy and safety of rabeprazole, amoxicillin, and gatifloxacin after treatment failure of initial Helicobacter pylori eradication. Helicobacter 2006; 11: $231-6$.

38 Kita T, Tanigawara Y, Aoyama N, Hohda T, Saijoh Y, Komada F, et al. CYP2C19 genotype related effect of omeprazole on intragastric $\mathrm{pH}$ and antimicrobial stability. Pharm Res 2001; 18: 615-21.

\title{
3rd Annual Regulatory Conference on Global Regulatory Challenges: Quest for Optimization
}

\author{
7-9 May $2010 \quad$ Mumbai, India
}

Organizer: DIA

Contact: Fahd Khan; phone: (91-9223267327)

E-mail: Fahd.Khan@diaindia.org 